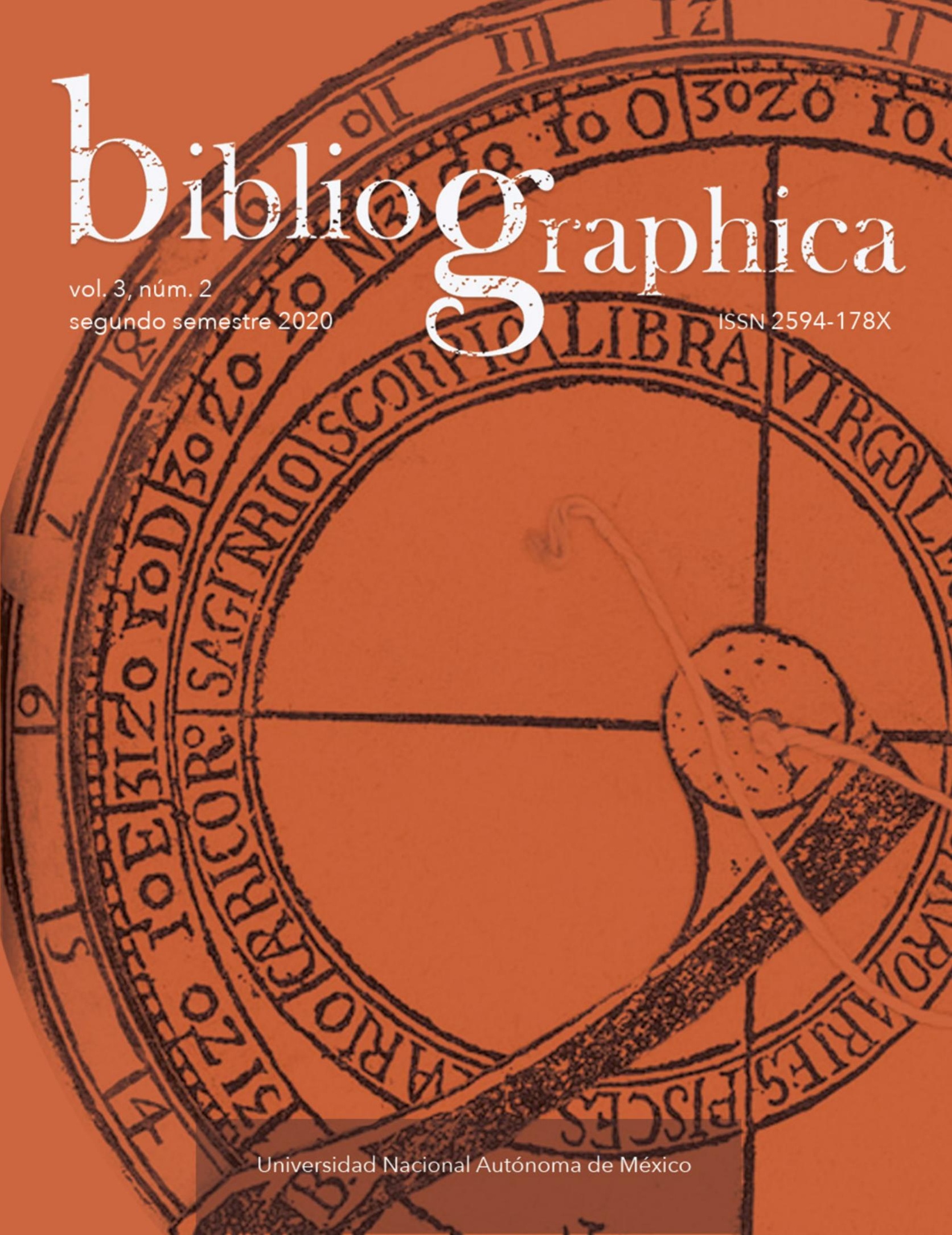




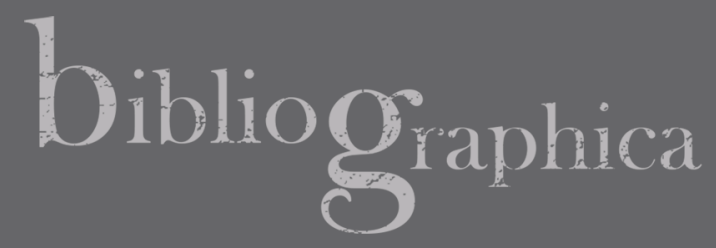

\section{Inventar títulos: un prospecto editorial de 1822 escrito por el Pensador Mexicano}

Inventing Titles: A Publishing Prospectus Written in 1822 by the Mexican Thinker

\section{Pedro Rueda Ramírez}

pedrorueda@ub.edu

Universidad de Barcelona

Facultad de Información y Medios Audiovisuales

Recepción: 24.03.2020 / Aceptación: 29.04.2020

DOI: https://doi.org/10.22201/iib.2594178xe.2020.2.81 
Resumen Estudio de un raro impreso con una lista de falsos títulos presentados como obras de José Joaquín Fernández de Lizardi, publicado en 1822 como prospecto editorial. Se hace un análisis comparativo del catálogo de los títulos inventados de Fernández de Lizardi con los de obras impresas en México y España a inicios del siglo XIX. La comparativa revela la escritura de los falsos títulos como ejercicio deliberado de imitación de los ya publicados sobre temáticas religiosas y políticas. Los títulos presentes en la lista conectaban con el horizonte de expectativas del lector. En conclusión, los títulos inventados apuntan hacia una orientación política de corte liberal y una crítica a los textos de los escritores contrarios al ideario del Pensador Mexicano, especialmente en el contexto de su excomunión en 1822 y la política de restricción de la libertad de prensa.

Palabras José Joaquín Fernández de Lizardi; imprenta; publicidad del libro; México; siclave glo XIX.

Abstract A study of a rare print featuring a list of fake titles presented as works by author José Joaquín Fernández de Lizardi, published in 1822 as an editorial prospectus. For this study, the catalogue of Fernández de Lizardi's titles was compared with real works published in Mexico and Spain at the beginning of the $19^{\text {th }}$ century. The comparison reveals that the invention of titles was a deliberate attempt to imitate existing political and religious works, and that it appealed to the horizon of expectations of the audience. To sum up, the fake titles pinpoint a liberal political stance and constituted a critique of the texts written by the Mexican Thinker's adversaries, especially in the context of the press censorship establishment and his own excommunication in 1822.

Keywords José Joaquín Fernández de Lizardi; printing press; book advertising; Mexico; $19^{\text {th }}$ century. 


\section{Porque hay -debe de haber en alguna parte- una inmensa biblioteca imaginaria de libros olvidados,}

no solo míos (que ya serían bastantes) sino de todo el mundo.

Jesús Marchamalo

Tocar los libros

\section{Introducción'}

En 1822 la imprenta mexicana de Mariano José de Zúñiga y Ontiveros (1749$1825)^{2}$ publicó un pequeño impreso titulado Tin tin, tin tin, tin tin. Hagan bien por el alma del Pensador Mexicano, con una lista de títulos que se publicarían. ${ }^{3}$ La impresión del documento en la imprenta de Zúñiga y Ontiveros por parte de Fernández de Lizardi adquiere un notable sentido ya que ese destacado impresor novohispano publicó 24 títulos suyos entre los años 1821 y 1825, además de numerosos impresos anónimos, algunos probablemente de su pluma, como el que nos ocupa.

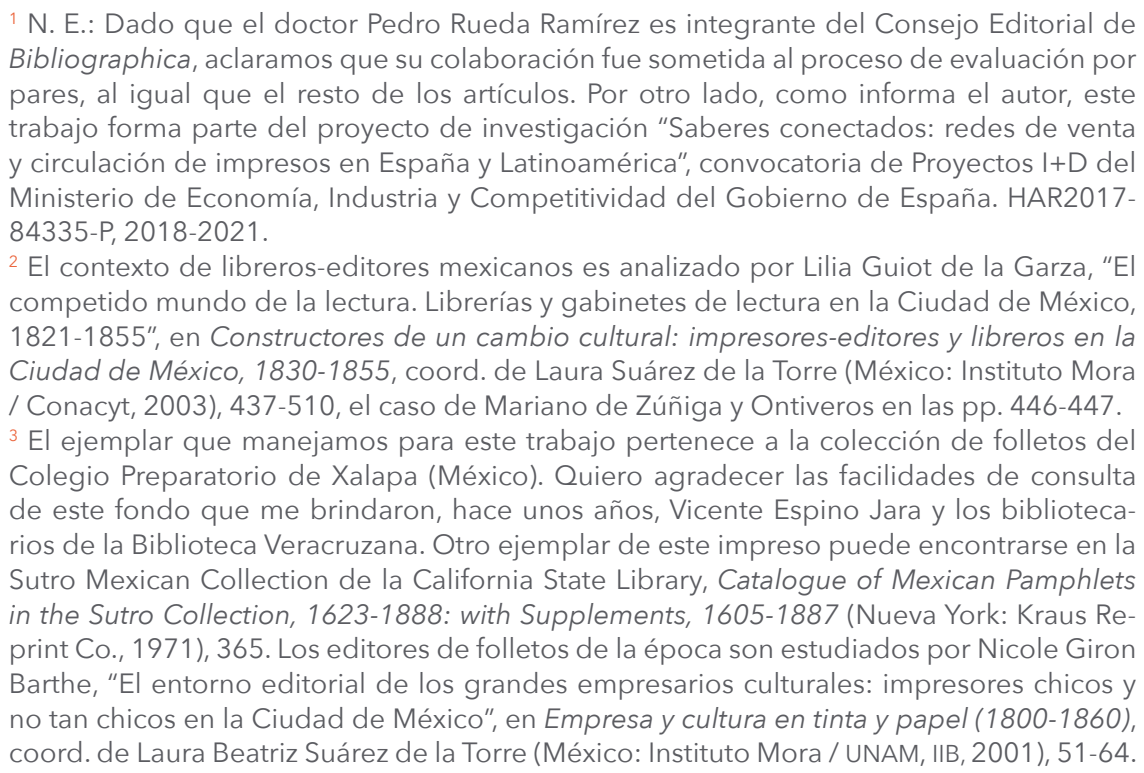


Este panfleto propagandístico ofrecía obras que se pondrían a la venta si despertaban el interés del público, siguiendo una senda iniciada por algunos editores, como José Alonso Padilla, que recuperaron las obras literarias del Siglo de Oro en el siglo XVIII. ${ }^{4}$ La finalidad era despertar la curiosidad del público lanzando anuncios, prospectos y editando catálogos de libros. ${ }^{5}$ Estas estrategias fueron un guiño al comprador, una suerte de aviso de textos recién editados, o en vías de publicación, que se basaba, en gran medida, en el título para atraer al comprador. ${ }^{6}$

José Joaquín Fernández de Lizardi había utilizado el sistema publicitario del prospecto al lanzar su novela El Periquillo Sarniento, mediante el Prospecto de la Vida o Aventuras de Periquillo Sarniento. Gratis a los suscriptores (México, 1815, 8 pp.). El público al que se dirigía Fernández de Lizardi adquiere una dimensión y unos perfiles específicos, y sus textos ofrecen constantes referencias a esos lectores que le sostenían, compraban sus textos y hacían que del Periquillo Sarniento se hicieran "mil y mil impresiones en los cuatro ángulos de la tierra".7

\footnotetext{
${ }^{4}$ Catálogo de libros exquisitos de la famosa librería Castellana de don Pedro Joseph Alonso y Padilla, Noticia preliminar de Agustín Hevia Ballina (Oviedo, 1977). Antonio Palau y Dulcet, Un folleto raro del librero de Madrid D. Pedro Joseph Alonso Padilla, 1747 (Barcelona, 1928). El caso inglés resulta igualmente interesante, por la diversidad de ventas y subastas que se producen, ver Lenore Coral, "Towards the Bibliography of British Book Auction Catalogues, 1801-1900", The Papers of the Bibliographical Society of America 89 (1995): 419-425.

${ }^{5}$ Antonio Rodríguez Moñino, Historia de los catálogos de librería españoles (1661-1840): estudio bibliográfico (Madrid: [Artes Gráficas Soler], 1966). María Jesús García Garrosa, "Publicidad y venta de novelas en España a finales del siglo XVIII", Bulletin of Spanish Studies 82, 1 (2005): 19-36. En torno al prospecto de librería, es recomendable Jean-Daniel Candaux, "Le premier âge d'or du prospectu", en Le livre entre le commerce et l'histoire des idées: les catalogues de libraires, $X V^{e}-X I X e$ siècle, ed. de Annie Charon, Claire Lesage y Eve Netchine (París: École des Chartes, 2011), 145-186.

6 Jean-Marc Buigues, "Los anuncios en la Gaceta de Madrid: inicios y desarrollo de la publicidad del impreso en España (1661-1696)", en Edición y propaganda del libro. Las estrategias publicitarias en España e Hispanoamérica (siglos XVII-XX), ed. de Lluís Agustí, Mónica Baró y Pedro Rueda Ramírez (Madrid: Calambur, 2018), 17-51. En el caso argentino es interesante el estudio de Alejandro E. Parada, El mundo del libro y de la lectura durante la época de Rivadavia: una aproximación a través de los avisos de la Gaceta Mercantil (1823-1828) (Buenos Aires: Universidad de Buenos Aires, Instituto de Investigaciones Bibliotecológicas, 1998).

${ }^{7}$ Raúl Marrero-Fente, "Don Catrín de la Fachenda: la ironía como expresión de una normativa vacilante", Acta Literaria, núm. 28 (2003): 109. Los mercados del libro en español en el siglo XIX son analizados por Jean-François Botrel, "Imprimés sans frontières au XIXe siècle
} 
La lista de los libros contiene referencias a otros títulos, en un ejercicio deliberado de imitación y parodia de títulos anteriores, que permite tender puentes con el receptor del folleto. Tal como Anne Cayuela expone al analizar los preliminares de obras literarias "la titulación de la obra -se podría llamar «intertitularidad» todo lo concerniente a los préstamos, plagios, influjos de unos títulos sobre otros- entra de lleno en la problemática de la reescritura". ${ }^{8}$ En general, en esta lista el título inventado depende del género al que desea adscribirse la obra. Éste sería el caso de "El purgatorio de S. Patricio y el purgatoriero Fernández", que utiliza un título conocido, la Vida y purgatorio del glorioso San Patricio de Juan Pérez de Montalbán, para conseguir que el receptor reconozca el género devoto y pueda detectar el sentido paródico empleado al atribuirle el texto al Pensador Mexicano, un escritor de corte liberal poco proclive a devociones en el año 1822, tras su enfrentamiento con los sectores católicos y su excomunión.

El bachiller Fernández se presentaba como autor del folleto, pero es evidente que se trata de Fernández de Lizardi "vestido" de aprendiz de escritor, encargado de defender la herencia del Pensador Mexicano y de elaborar una "Enciclopedia Lizarduna". Este último título era presentado como obra de divulgación del saber. Ésta era la intención de Fernández de Lizardi expresada en El Payazo de los periódicos (México, 1823, 8 pp.), texto en el cual apuntaba que escribía para "acomodarnos a todos, al gusto de los sensatos y al de los ignorantes. Queremos que los pobrecitos de la última plebe nos entiendan; que se enamoren de nuestro estilo llano y popular".9 Para lograrlo llegó a publicar una decena de periódicos, entre 1812 y 1827, y a redactar 194 folletos entre 1811 y $1824 .{ }^{10}$

(France / Espagne / Amérique Latine)", en Les transferts culturels. L'exemple de la presse en France et au Brésil, dir. de Valéria Guimarães (París: L'Harmattan, 2011), 49-62.

${ }^{8}$ Anne Cayuela, "De reescritores y reescrituras: teoría y práctica de la reescritura en los paratextos del Siglo de Oro", Criticón 79 (2000): 38.

9 José Joaquín Fernández de Lizardi, Some Newly Discovered Poems and Pamphlets of J. J. Fernández de Lizardi (El Pensador Mexicano), prepared under the direction of Paul Radin ([San Francisco: California State Library, 193?]), 12.

${ }_{10}$ María Rosa Palazón Mayoral, Prólogo a Obras, vol. 12: folletos (1822-1824), de José Joaquín Fernández de Lizardi (México: UNAM, 1991), ix-lviii. 


\section{Catálogo de títulos}

El anuncio de los títulos conforma un catálogo editorial que sirve como reclamo del interés del lector $y$, en otros casos, para dar a conocer la lista de libros disponibles o en circulación en un mercado que puede ser local, pero que en el caso americano tiene siempre presentes los circuitos del intercambio atlántico." Este tipo de catálogos, como acertadamente advierte Víctor Infantes, "no casa en ocasiones con nuestras premisas clasificatorias". ${ }^{12}$ Están dirigidos en este caso a un lector hipotético y constituyen una retahíla de títulos inventados, que en sí mismos son el contenido textual y la justificación del panfleto editado. En alguno de los títulos de las obras se intentaba imitar un sentido de oferta de totalidad de las "Opera omnia, et de omnibus" del Pensador, "con anotaciones de Fernández", siguiendo la estela de las partes de obras sin fin de algunos autores y colecciones teológicas y jurídicas. Tal como señala Kurt Spang, es conveniente recalcar la "importancia de la colaboración reconstructiva del receptor y del conocimiento de las variaciones históricas de la titulación para el cabal entendimiento del título". ${ }^{13}$ Es un aspecto que los autores de la época resaltaron, como Alonso de Herrera, quien destacaba cómo "los ilustres títulos de los libros suelen convidar muchas veces a los curiosos a que los compren". ${ }^{14}$ La titulación destaca, sin duda, como el medio de publicidad más efectivo para atraer al lector.

Contribuye al tono jocoso del folleto que los papeles por imprimir del Pensador Mexicano puedan distribuirse no como solían, en breves impresos voceados por las calles, sino como una obra en varios volúmenes, tal como aparecían las obras de autores consumados, o las ediciones costosas compradas por aristócratas o académicos. Era una irreverencia presentar al Pensador en varios volúmenes, en cierto modo una burla de las apariencias sociales y el prestigio de algunas de estas suscripciones. En ocasiones las listas de suscripción

\footnotetext{
11 José Simón Díaz, El libro español antiguo: análisis de su estructura (Kassel: Reichenberger, 1983), 51-83. Alfredo Serrai y Fiammetta Sabba, Profilo di storia della bibliografia (Milán: Bonnard, 2005), 202-212. El caso norteamericano es analizado por Robert B. Winans, "The Beginnings of Systematic Bibliography in America up to 1800: Further Explorations", The Papers of the Bibliographical Society of America 72 (1978): 15-35.

12 Víctor Infantes, Del libro áureo (Madrid: Calambur, 2006), 23.

${ }^{13}$ Kurt Spang, "Aproximación semiótica al título literario", en Investigaciones semióticas I: Actas del I Simposio Internacional de la Asociación Española de Semiótica, celebrado en Toledo durante los días 7, 8 y 9 de junio de 1984 (Madrid: CSIC, 1986), 535.

${ }^{14}$ Alonso de Herrera y Molina, Discursos predicables de las excelencias del nombre de lesus, y de los nombres y atributos de Christo (Sevilla: Gerónimo de Contreras, 1619), 9r-11r.
} 
eran públicas y se conocían, al ser enlistadas al final de las obras. Esto otorgaba al lector un plus de reconocimiento social y de estatus culto en el juego de apariencias de la república de las letras. El uso de la suscripción es, en este sentido, un mundo al revés, una reutilización simbólica del papel del saber, que pasó de lo exclusivo de la distribución por suscripción de los tiempos de la Colonia a la popularización de los textos mediante el uso de la prensa y los libros vendidos a plazos. El traspaso de tal frontera supuso la construcción, deliberada, de un espacio público para el debate y la confrontación de ideas.

La intención apunta a una clara orientación política de corte liberal y un ataque audaz a los autores contrarios al ideario de Lizardi. Fue algo bastante frecuente y recuerda a las batallas de libros, que conformaron un fenómeno discursivo en las críticas ilustradas a los demasiados libros y el exceso de las traducciones. ${ }^{15}$ El cúmulo de novedades posible dependía de un público ávido de noticias que devoraba gacetas, compraba textos y se dejaba llevar por la lectura de novelas. En este sentido, convendría citar un interesante caso que reúne ambos fenómenos al tratar de una insurrección de libros franceses en una librería lisboeta en 1808. En un Aviso ao público sobre os estragos feitos nos libros franceses (Lisboa, 1808) el mercader de libros João Baptista Reycend avisa que "havendo sucedido na sua Loja huma insurreição, e revolução dos livros, huns com os outros" se extraviaron y desertaron "principalmente os das novissimas impressões e gosto parisiense". ${ }^{16}$ Los 19 libros extraviados tenían unos títulos, como era de esperar, repletos de ironía, por ejemplo el caso de la Fabrica de Gazetas, Electrica de mentiras, Fysica dos signaes falsos. Se trataba de una falsificación bibliográfica realizada por un librero con 50 años de experiencia en el negocio (desde 1758 hasta 1808). En este caso se elaboró un falso catálogo, una lista burlesca de libros imposibles. La lista tuvo, también, un contenido político en una acedada crítica antifrancesa, en un momento delicado como fue 1808, con los títulos de As cinco virtudes que experimentou o povo de Lisboa aos 10 dias de chegada dos Francezes o el Certamen poetico sobre a força das Syllabas...v. g. Napoleão, Cabrão, Ladrão.

\footnotetext{
15 Marc Fumaroli, Las abejas y las arañas: la querella de los antiguos y los modernos (Barcelona: El Acantilado, 2008); José Francisco Ruiz Casanova, Ensayo de una historia de la traducción en España (Madrid: Cátedra, 2018), 376-381.

${ }^{16}$ Manuela D. Domingos, "Os catálogos de livreiros como fontes da história do libro: o caso Dos Reycend", en V Centenário do Livro Impresso em Portugal, 1487-1987: Colóquio sobre o Livro Antigo, Lisboa, 23-25 de maio de 1988: Actas (Lisboa: Biblioteca Nacional, 1992), 305-322.
} 


\section{Una lista de luto}

El impreso de Lizardi que analizamos está planteado como un ejercicio de luto por el alma del difunto Pensador Mexicano, pues están comprendidos documentos con el pésame de la viuda, las "Exequias del pensador", su testamento y los "Ayes y suspiros de los amigos del Pensador". El título Tin tin, tin tin, tin tin. Hagan bien por el alma del Pensador Mexicano resulta ser una llamada piadosa para atender al difunto, y el grabadito xilográfico de la portada -con una calavera con las tibias cruzadas-, un recordatorio de los textos devotos que llamaban a despertar la conciencia ante la hora de la muerte. El juego simbólico se refuerza al usar estos elementos propios de los impresos devocionales novohispanos.

Esta retórica sonora volvería a emplearse en un texto de 1826 de Joaquín Fernández de Lizardi titulado Hagan bien: tilin, tin, tin, por el alma del gachupín. Es, a la par, un reclamo con su punto de ironía y una advertencia al lector del tono del contenido. ${ }^{17}$ Exequias literarias y edición póstuma se aúnan para reunir a los lectores futuros de los textos del difunto, ofreciendo mediante las prensas una herencia textual reconocible. Es un artificio, como bien podemos calcular, que va dirigido a lectores avezados en las trifulcas panfletarias, jugando, en este caso, a la aventura postmortem de la memoria del Pensador Mexicano, puesta a salvo por uno de sus discípulos.

Cada entrada juega, como cabía esperar, en una reescritura de títulos anteriores; veamos algún caso significativo. La "Oración fúnebre por el Br. Sansón Carrazco" hacía alusión a la Enfermedad, muerte y entierro de la Constitución por el bachiller Sansón Carrasco, un breve texto difundido tras el retorno de Fernando VII y la pérdida de la Constitución de 1812. ${ }^{18}$ Que este bachiller Sansón Carrasco diera la oración fúnebre del Pensador Mexicano y ésta se imprimiera resultaba irónico, teniendo presentes los ataques del clero al ideario de José Joaquín Fernández de Lizardi. El tintineo deliberado del comienzo es un guiño al lector, al que no le podía pasar desapercibida la excomunión de Fernández de Lizardi. Un proceso en el que jugó un papel clave su respuesta a una agria

\footnotetext{
${ }_{17}$ Paul Radin, "An Annotated Bibliography of the Poems and Pamphlets of Fernández de Lizardi (1824-1827)", Hispanic American Historical Review 26, núm. 2 (1946): 290.

${ }^{18}$ Enfermedad, muerte y entierro de la Constitución por el bachiller Sansón Carrasco (Sevilla: Imp. del Correo Político a cargo de Manuel Valdivares, 1814).
} 
polémica, una más de las que mantuvo Lizardi, publicada en la ¡Carta primera del Pensador al Papista! (en México por la Imprenta de Betancourt, en 1822). ${ }^{19}$

TIN TIN, TIN TIN, TIN TIN.

HAGAN BIEN

POR EL ALIMA

DEL PENSADOR MEXICENO.

SUFRAGTO DEL BR, D, HERMENEGILDO FERNANDEZ *

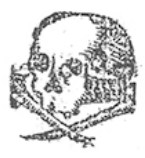

unto á la Pulqueria de Cuajomucho, casa 238 accesoria Krepetida, rectbe sutscripciones el maestro amolador a las obras y papeles sigutentes, que trata de publicar el Bro D. Hermenegildo Fernandez, bajo los títulós que se leerăn. Sera su precto el de 20 pesos, la impresion antuerpiana, en la imprenta impeŕtíl, real y pontificia de la bula de la Cruzada que fué del difunto Pensador mexisano, la encuadernación á la rústica.

Figura 1. Tin tin, tin tin, tin tin. Hagan bien por el alma del Pensador Mexicano

(México: Mariano Zúñiga y Ontiveros, 1822), 1.

\footnotetext{
${ }^{19}$ Luis González Obregón, Don José Joaquín Fernández de Lizardi (El Pensador Mexicano) (México: Ediciones Botas, 1938), 123-130. José Joaquín Fernández de Lizardi, Obras, vol. 12: folletos (1822-1824) (México: UNAM, 1991).
} 
El segundo de los títulos inventados que aparecen en esta bibliografía es la Aparición del alma del Pensador, al excomulgarlo. Tampoco falta una Vida y milagros del Pensador, una entrada que sigue la manera tradicional de titulación de las vidas de beatos y santos. ${ }^{20} \mathrm{El}$ texto busca cierta inversión burlesca. Usando los elementos de reclamo de la buena muerte del cristiano, se intenta llamar la atención, como si de una invitación a la lectura de textos piadosos se tratara. En opinión de Beatriz de Alba-Koch, al tratar el tema de la muerte "Lizardi seculariza un motivo barroco para conformarlo a sus propósitos educativos ilustrados". ${ }^{21}$ En este caso, en el contexto de la polémica tras su excomunión.

La excomunión del año 1822 es clave para la interpretación del Hagan bien por el alma del Pensador Mexicano que estamos analizando. El contexto político de estos complicados años puede seguirse en el Bosquejo ligerísimo de la revolución de Méjico, desde el grito de Iguala hasta la proclamación de Iturbide (Filadelfia, 1822). Un punto de vista muy diferente, en fuentes españolas, en el Compendio de los acontecimientos de Nueva España desde el año de 1820 hasta la pérdida de aquella parte de la Monarquía española (Coruña, 1822).

En otro folleto lizardiano titulado Ya el pensador mexicano se declaró por herege, dos personajes, Lázaro y Rafael, conversan en torno a la muerte del alma del Pensador Mexicano y su probable (o no) resurrección. En un momento dado Lázaro alude a que al "Pensador Mexicano lo mataron el 22 de febrero último, fulminando contra él una excomunión, que se fijó aquel mismo día en varios parajes públicos". ${ }^{22}$ Es la clave para entender el Hagan bien por el alma del Pensador Mexicano, pues en el folleto se presenta la "Muerte pensada o imaginada del Pensador mexicano por sus pecados de pensamiento". No en vano, en el folleto Ya el pensador mexicano se declaró por herege, se afirmaba que "bien es verdad que aunque muerto, está siguiendo su pleito". En cierto modo, la lista de títulos que analizamos formaba parte del pleito de descargo de Fernández de Lizardi contra sus enemigos, tras la excomunión y consiguiente "muerte" de su alma, dictada por orden eclesiástica.

\footnotetext{
20 José Simón Díaz, "Hagiografías individuales publicadas en español de 1480 a 1700", Hispania Sacra 30 (1977): 421-480.

${ }^{21}$ Beatriz de Alba-Koch, Ilustrando la Nueva España: texto e imagen en el Periquillo Sarniento de Fernández de Lizardi (Cáceres: Universidad de Extremadura, 1999), 76.

22 Ya el pensador mexicano se declaró por herege (México: Imprenta de doña Herculana del Villar y Socios, 1822), 2, acceso el 9 de junio de 2020, http://bibliotecadigitalhispanica. bne.es.
} 
El 13 de febrero de 1822, Lizardi publicó la Defensa de los Francmasones, que dio origen a su excomunión. ${ }^{23}$ La reacción fue inmediata. En un panfleto firmado por F. V. Y. titulado la Manifestacion de los frac-masones. Dedicada para su conversion al Pensador Mexicano (1822) se insiste en la existencia de sectas masónicas que "aspiran a la total libertad de religión y de costumbres: a la esención de todo gobierno y autoridad", ${ }^{24}$ y es en este contexto en el que hay una auténtica guerra de panfletos. ${ }^{25} \mathrm{El}$ autor que firma como F. V. Y. no puede dejar de recalcar la "libertad de religión" como algo destructivo. Al sacar Fernández de Lizardi los debates a la plaza pública e insistir en temáticas religiosas, provocó una fuerte reacción.

Para algunos autores estos asuntos debían estar fuera de toda duda, bajo obediencia absoluta, pues, "¡Que verguenza, que hombres que pasan por tan eruditos no peleen con otras armas que las de las verduleras!". ${ }^{26}$ El papel clave de Lizardi en contra de algunas de las opiniones conservadoras les resultaba intolerable, ya que "El Pensador mexicano [...] habiendo sido declarado excomulgado vitando, se asegura, que sigue terco y pertinaz en sus errores. ¡Infeliz! Roguemos a Dios por él". ${ }^{27}$

Este es el ambiente en el que se enmarca el folleto que analizamos, en un debate político y religioso de ideas enfrentadas en torno a la libertad religiosa, y de definición de los límites de la opinión impresa. En esos años, entre 1812 y 1822, Fernández de Lizardi se ocupó de algunos temas clave para los pensadores liberales, tal como analiza Jefferson Rea Spell al ocuparse de su faceta como autor de panfletos, escribió sobre "free press, he devoted himself to the complex political problems then facing the Mexican nation". ${ }^{28}$

Su trayectoria como escritor se había apuntalado en los resquicios mismos de la permisividad de la norma, desde la primera aprobación de la libertad de imprenta en 1812, aunque a raíz de sus artículos pronto fue restringida y

\footnotetext{
${ }^{23}$ González Obregón, Don José Joaquín Fernández, 52-54.

${ }^{24}$ Manifestacion de los frac-masones. Dedicada para su conversion al Pensador Mexicano ([México]: Imprenta Imperial de D. Alejandro Valdés, 1822), 3.

${ }_{25}$ María Eugenia Vázquez Semadeni, La formación de una cultura política republicana: el debate público sobre la masonería, México, 1821-1830 (México: UNAM, IIH / El Colegio de Michoacán, 2010).

${ }^{26}$ Manifestacion de los frac-masones, 5.

${ }^{27}$ Ibid., 6.

28 Jefferson Rea Spell, "Fernandez de Lizardi as a Pamphleteer", The Hispanic American Historical Review 7, núm. 1 (1927): 105, 113-114.
} 
suspendida, para volver a ser restituida en 1820. Fernández de Lizardi publicaría en 1821 un Proyecto sobre libertad de imprenta, pero las restricciones a la libertad de prensa del gobierno provisional lo llevaron a publicar en abril de 1822 Maldita sea la Libertad de la Imprenta. La tensión con las autoridades fue constante en su búsqueda de espacios de debate político, pero también de apertura a públicos diversos y lectores populares. Esto lo llevaría a proponer en 1820 la apertura de una Sociedad Pública de Lectura, similar a los gabinetes que funcionaban en Europa, ya que "muchos no leen no porque no saben o no quieren sino porque no tienen proporción de comprar cuanto papel sale en el día".29

El año de publicación de Hagan bien por el alma del Pensador Mexicano fue un momento de crisis, uno más, en las tensiones con las autoridades políticas y eclesiásticas en torno a los límites de la escritura, la prensa y la libertad de imprenta. En 1823 el jefe político Molinos del Campo mandó prohibir el voceo de los impresos por las calles y, además, prohibió "los rubros o títulos alarmantes, injuriosos y subversivos". ${ }^{30}$ Es un asunto clave que revela la importancia de los títulos para lograr retener la atención de los oidores, que reciben las noticias en titulares, voceadas en las calles, y pueden comprar el periódico o folleto por la publicidad.

En Hagan bien por el alma del Pensador Mexicano no podía faltar el anuncio de un impreso titulado "Pucheros y sentimientos de los muchachos vendedores de papeles". Estos vendedores eran los que voceaban sus textos, por lo que sus lamentos eran dobles, por la pérdida de un escritor reconocido y por la pérdida de una fuente de sustento al vender sus textos. La polémica generada por la excomunión de Fernández de Lizardi tocó de lleno la restricción de la libertad de prensa en torno a asuntos que tocaran la religión. ${ }^{31}$

En cualquier caso, el debate tuvo su origen, entre otras fuentes, en las sesiones constitucionales gaditanas, y tuvo antecedentes de gran interés en

\footnotetext{
${ }^{29}$ Analizan el folleto en el que se incluye esta propuesta, Mariana Ozuna Castañeda y María Esther Guzmán Gutiérrez, "Para que todos lean: La Sociedad Pública de Lectura de El Pensador Mexicano", en Empresa y cultura en tinta y papel (1800-1860), coord. de Laura Beatriz Suárez de la Torre (México: Instituto Mora / UNAM, IIB, 2001), 274-284.

${ }^{30}$ Irma Isabel Fernández Arias, "Calas en el pensamiento de Fernández de Lizardi referente a la libertad de expresión", en Actas del XII Congreso de la Asociación Internacional de Hispanistas, 21-26 de agosto de 1995 (Birmingham, 2007), 176-181.

31 Will Fowler, Mexico in the Age of Proposals, 1821-1853 (Westport, CT; Londres: Greenwood Press, 1998), 169-217.
} 
México, como revela, entre otros textos, la defensa de la libertad de imprenta de El corneta de las imprentas (1812). ${ }^{32}$ La libertad de prensa fue un argumento esencial en los primeros debates políticos interesados en la constitución de una esfera pública. ${ }^{33}$ Para Victor Uribe-Uran, la libertad de prensa se constituyó en un eje de las discusiones entre conservadores y liberales, entre otros grupos, ya que permitía discutir ideas, reunir votos para las elecciones y favorecer la consolidación de los argumentos constitucionales de derechos que fueron una base esencial en los debates de las nuevas ciudadanías latinoamericanas en los años que fueron de 1820 a $1850 .{ }^{34}$

Fernández de Lizardi defendió dicha libertad como una herramienta clave para contener el despotismo, y sus polémicas periodísticas las veía como una oportunidad para la discusión de sus ideas liberales, aunque en modo alguno el conjunto de los panfletistas pueden etiquetarse igual, tal como advierte Rafael Rojas "los nuevos mecanismos de opinión pública y de sociabilidad política que se forman a partir de 1822 requieren de este personaje funcional", aunque su papel fuera transitorio y fueran en numerosos casos sujetos marginales, que serían utilizados por algunos caudillos y políticos, pero finalmente quedaron desplazados en la articulación de las nuevas élites nacionales. ${ }^{35}$

El impreso sería, por tanto, un texto publicitario de los títulos que se pondrían a la venta tras lograr un éxito de público interesado. Aunque al menos un texto que figura en esta lista, en concreto el Testamento del pensador, fue realmente publicado con ese título en 1827 como Testamento y despedida del pensador mexicano, en dos partes, una Primera parte (8 pp.) y una Segunda parte y conclusión (8 pp.). ${ }^{36}$ Es, probablemente, una deliberada coincidencia. En realidad la lista era, como podemos imaginar, un artificio en sí mismo bien construido, para simular la continuidad de la memoria y la construcción de la preservación de la ideología del Pensador Mexicano.

${ }^{32}$ El corneta de las imprentas. Reflexiones joco-serias (México: Imprenta de D. Juan Bautista de Arizpe, 1812), acceso el 9 de junio de 2020, http://bibliotecadigitalhispanica.bne.es.

${ }_{33}$ Manuel Peña Díaz, José Isidoro Morales y la libertad de imprenta (1808-1810) (Huelva: Universidad, 2008).

${ }^{34}$ Victor M. Uribe-Uran, "The Birth of a Public Sphere in Latin America during the Age of Revolution", Comparative Studies in Society and History 42, núm. 2 (2000): 453.

${ }_{35}$ Rafael Rojas, La escritura de la Independencia. El surgimiento de la opinión pública en México (México: Taurus / CIDE, 2003), 171.

${ }^{36}$ Radin, "An Annotated Bibliography...", 291. 
El impreso de 1822 contiene un lote de papeles que resultan ser una invención, un catálogo de obras imposibles, tal como conviene a las burlas presentadas como verdades por imprimir, bajo el auspicio del público suscriptor. De este modo, el texto recoge una fórmula de píldoras de información previa a la salida al mercado de los impresos, contando el suscriptor tan sólo con el atractivo del título de las obras. En el mundo moderno el título es la clave esencial de los contenidos y el lector compra, consume e incluso tiene una guía de lectura del contenido, enraizado en la intitulación de la obra.

En la guerra de las letras, el debate en torno a los títulos no podía faltar, Luis Antonio Verney al ocuparse del Verdadero método de estudiar (Madrid, 1760) se refería a sus contemporáneos que "no se contentan con poner el título de el libro claro, sino que, o inventan uno estrambótico, o añaden algún epíteto, que obscurece el negocio", y es usado en gran medida por los autores de "erudición afectada" que usaban "títulos ridículos, que solo estaban bien en la boca de Don Quixote de la Mancha". ${ }^{37}$

El mismo problema de la titulación de las obras fue planteado por José Francisco de Isla, quien alababa que "ni Tito-Livio, ni Cornelio Nepote ni algún otro autor de los del Siglo de Augusto usaron jamás de títulos rumbosos, sino simples y naturales", ${ }^{38}$ un argumento que conviene resaltar, ya que los nombres del folleto jugaban con la titulación e intentaban ir directo contra esa afectación, tan corriente en los títulos de los tratados católicos barrocos y en los de algunos de los enemigos de Fernández de Lizardi.

\section{Conclusiones. El arte de inventar títulos}

En el mundo europeo moderno, la burla con títulos se desarrolló como sátira política, desde Rabelais a la llustración. ${ }^{39}$ En algunos casos, la invención de títulos fue un medio para generar una crítica del poder en forma de parodia contra

\footnotetext{
${ }^{37}$ Luis Antonio Verney, Verdadero metodo de estudiar para ser util a la Republica y a la Iglesia ... tomo segundo (Madrid: Joachin Ibarra, se hallara en casa de don Marcos Ruiz de Tejada, 1760), 46.

${ }^{38}$ José Francisco de Isla, Historia del famoso predicador Fray Gerundio de Campazas, alias Zotes (Madrid: Imp. de Gabriel Ramírez, 1804), 1, 151-152.

${ }^{39}$ Anne-Pascale Pouey-Mounou y Paul J. Smith, eds., Early Modern Catalogues of Imaginary Books: A Scholarly Anthology (Leiden: Brill, 2019). Aborda la idea de novedad, y la transformación de las prácticas de lectura, James van Horn Melton, La aparición del público durante la llustración europea (Valencia: Universidad de Valencia, 2009), 121-122.
} 
la Corona y los gobernantes, en otros casos fue una manera de exponer las corrientes filosóficas de la llustración. ${ }^{40}$

Un interesante ejemplo de sátira política fue el "Indice de libros nuevos por diuersos autores impressos en Madrid desde 17 de setiembre de 1665". Este manuscrito corrió en copias de mano que contenían los supuestos títulos "nuevos" recién publicados. ${ }^{41}$ Cada obra era atribuida a un hombre de la Corte o del gobierno, con notable burla de sus habilidades. Al confesor real se le atribuía un "Breve artificio con que sera un hombre para todo no siendo para nada libro de gusto aunque con poco ingenio autor el confesor de la reyna", o el libro "Otro arte de conseguir quales quier medios libro político autor el conde de Castrilo", título en que se hacía eco de los supuestos pocos escrúpulos del presidente del Consejo de Castilla, García de Haro y Guzmán, conde de Castrillo (1585-1668). Títulos imaginarios que servían para satirizar el quehacer político y cortesano de hombres poderosos que no eran, precisamente, autores de libros reconocidos ni eran valorados por sus letras.

Estos libros anunciados no podían ni conseguirse ni leerse, aunque a nadie entendido que leyera los títulos se le podía escapar el tono de ironía y las dosis de crítica. Esto entra de lleno en la afición a los textos imposibles, aquellos que se logran inventando la bibliografía más pertinente, pero que se fundamentan en una impostura de libros inexistentes.

El coleccionista y bibliógrafo Pierre Gustave Brunet redactó un Essai sur les bibliothèques imaginaires (1862), en línea con otros textos suyos sobre libros inexistentes. Es también el caso del Manuel de la bibliographie des livres jamais publiés ni même écrits, una idea expuesta por el escritor Blaise Cendrars (18871961), con la finalidad de redactar un libro que contendría citas, catálogos y críticas de libros inventados. La invención de la invención.

Algo de esto hay en nuestro impreso, pues el listado de obras que saldrían a la plaza pública incluía el "Inventario de los libros y estantes del Pensador" realizado por "su aprendiz de marras", en realidad el mismo Hermenegildo Fernández, que aparentemente es el editor literario del folleto y de su obra y que, finalmente, es otra identidad del mismo Fernández de Lizardi.

\footnotetext{
${ }^{40}$ Peter-Eckhard Knabe, "The Battle of the Books ou la conquête du nouveaux espaces", en L'aube de la modernité, 1680-1760 (Filadelfia: John Benjamins Publishing Company, 2002), 5-14.

${ }^{41}$ Biblioteca Nacional de España, ms. 9397, núm. 6, 21 r.
} 
El difunto excomulgado tuvo tiempo para escribir y se anuncia como uno de sus escritos "Berrinches y ojeriza del Pensador, aún después de muerto, contra el Br. Fernández", pues parecía que su heredero intelectual, el bachiller Hermenegildo Fernández, quería hacerse con el bagaje de sus posesiones terrenales, incluyendo a la viuda. En realidad el bachiller es un alter ego del Pensador Mexicano, lo cual le permite acabar la lista de títulos inventados con una comedia, que cierra el juego simbólico de la burla. La comedia contaría "El casamiento imposible del Br. Fernández con la Pensadora, viuda del Pensador". Una boda que no podía celebrarse, pues Fernández de Lizardi seguía vivo, y su "aprendiz" tendría que buscar otro oficio, sin vivir de las rentas de editar los textos de otro.

\section{Apéndice}

Folleto con la lista de títulos inventados de José Joaquín

Fernández de Lizardi (1822)

[p. 1]

Tin tin, tin tin, tin tin. Hagan bien por el alma del Pensador Mexicano. Sufragio del Br. D. Hermenegildo Fernández. [Grabadito xilográfico de una calavera con unas tibias cruzadas]

Junto a la pulquería de Cuajomucho, casa 238 accesoria K repetida, recibe subscripciones el maestro amolador a las obras y papeles siguientes, que trata de publicar el Br. D. Hermenegildo Fernández, bajo los títulos que se leerán. Será su precio el de 20 pesos, la impresión antuerpiana, en la imprenta imperial, real y pontificia de la bula de la Cruzada que fue del difunto Pensador mexicano, la encuadernación a la rústica.

[p. 2]

Títulos de las obras.

Pésame que da a la viuda del Pensador, la hermana de dicho Br. Fernández. ${ }^{42}$ Aparición del alma del Pensador, al excomulgado $\mathrm{H}$.

\footnotetext{
${ }^{42}$ La forma de "pésame" fue adoptada por algunos panfletos, como el de José de San Bartolomé, El duelo de la Inquisición ó pésame que un filósofo rancio dá a sus amados compatriotas (México, 1814).
} 
Exequias del Pensador. ${ }^{43}$

La calabera y huesos del Pensador. ${ }^{44}$

Pesadilla que tuvo la viuda del Pensador en la noche de su infanda muerte.

La pira del mismo, y colección de varios epitafios. ${ }^{45}$

Oración fúnebre por el Br. Sanson Carrazco. ${ }^{46}$

El purgatorio de S. Patricio y el purgatoriero Fernández. ${ }^{47}$

Testamento del Pensador. ${ }^{48}$

Pensador. Opera omnia, et de omnibus, con anotaciones de Fernández.

${ }^{43}$ Las exequias son una de las fórmulas comunes adoptadas por los sermones impresos. El hecho de que se anuncie la impresión de unas exequias por un excomulgado como Fernández de Lizardi debe interpretarse en clave de ironía, más si tenemos en cuenta que solían realizarse tales exequias fúnebres para honrar a miembros destacados del gobierno y de la Corona, como es el caso de Jorge Comin (O. de M.), Exequias a la Reyna de las Españas Doña María Josefa Amalia de Sajonia ([Valencia, 1829]).

${ }_{44}$ Un nuevo ejemplo de inversión burlesca. La alusión a la calavera recuerda las artes de la muerte y, de nuevo, los sermones fúnebres, como el de Faustino Garroverea (O. Minim.), Los huesos visitados, y que profetizan después de la muerte: oración fúnebre, que en la solemne deposicion del cadaver del P. F. Josef Ibañes de la Consolación ([Zaragoza, 1816]). ${ }^{45}$ El título remite a las piras funerarias y poesías laudatorias de difuntos, tan habituales en la literatura de ocasión del momento, sobre todo en la muerte de cabezas coronadas, seglares y seculares, tal como pusieron de manifiesto los Adornos de pintura y poesía. Elogio sepulcral con que se cubrió la Pira y Oraciones fúnebres que se dijeron en las solemnes exequias celebradas por la Santa Iglesia Catedral de Valladolid de Michoacan para honrar la memoria del Señor Carlos Antonio de Borbón (México, 1820).

${ }^{46} \mathrm{El}$ título remite directamente a un panfleto político reivindicativo del que se realizaron varias ediciones en los años 1813-1814, justamente para reclamar la pérdida de la Constitución gaditana. Sansón Carrasco, Enfermedad muerte y entierro de la Constitución (Granada, [1813]).

${ }^{47}$ La Vida y purgatorio de San Patricio (1627), de Juan Pérez de Montalbán, fue una obra de notable éxito que narraba la vida del apóstol y patrón de Irlanda, así como su estancia en la cueva que conducía, según la leyenda, al infierno. En este caso hace alusión al "purgatoriero" Fernández, que debía vivir la misma prueba del santo de pasar una noche en la cueva para purgar sus pecados.

${ }^{48}$ El título contiene referencias -claras para los contemporáneos- a obras católicas como el Testamento de San Carlos Borromeo, editado con frecuencia en esos años, pero que ya había sido objeto de un giro completo en otros panfletos, como testamento político de últimas voluntades ideológicas, o un instrumento de crítica a instituciones, por ejemplo en el Testamento y ultima voluntad de la Santa Inquisicion y publica declaracion de sus culpas (Impresa en Madrid y por su original en México, 1820). 
Vida y milagros del Pensador. ${ }^{49}$

Bendición y últimos consejos del Pensador a sus queridos sectarios, y

despedida tierna del Bocadillero.

Ayes y suspiros de los amigos del Pensador. ${ }^{50}$

Llantos de los literatos y de Minerva.

Pucheros y sentimientos de los muchachos vendedores de papeles. ${ }^{51}$

Honras fúnebres de la nacional Universidad mexicana.

El probabilismo, liberalismo, servilismo, y prodigalismo, libres de la nota de ruti-

neros, por el mismo difunto Pensador, con una análicis [sic] de Fernández.

Enciclopedia Lizarduna.

Arte de dicharachos, retobos y refranes por el referido satírico difunto. ${ }^{52}$

Lo que puede la fuerza del pico y del arrojo, por Fernández.

\footnotetext{
${ }^{49}$ Fernández de Lizardi aprovecharía diversas oportunidades para ofrecer un giro burlesco a esta tipología de títulos de raigambre religiosa, tal como hizo en la Vida y entierro de don Pendón. Por su amigo El Pensador (México, 1822), recogida en sus Obras, vol. 12 (México: UNAM, 1991), 107-113.

${ }^{50}$ Los suspiros, igualmente, pueden remitir tanto a obras religiosas que conectan al lector con la Pasión, o bien una apropiación muy diferente de tales suspiros por parte de los exiliados, cargando, de este modo, de contenido político los argumentos del título, tal como se observa en las Quexas y suspiros de los afrancesados: copia de una carta que escribe un desesperado afrancesado desde París á un amigo que tiene en esta Corte, el que le dió buenos consejos en otros tiempos (Madrid, 1814). El cambio de los tiempos y la turbulencia política generan estos "suspiros de los afrancesados", obligados a marchar y a vivir sin lograr sus aspiraciones.

${ }^{51}$ Estos llantos de los que pregonaban sus papeles impresos por las calles tuvieron ecos interesantes en los debates en torno a la libertad de imprenta. En la sesión de las Cortes del 25 de enero de 1822 se ocuparon ampliamente de estos vendedores de papeles, la licencia que debían solicitar y qué títulos podían pregonar. La polémica estaba servida y Fernández de Lizardi contaría con el favor y las lágrimas de estos vendedores. Diario de las actas y discusiones de las Cortes estraordinarias de 1821, vol. 3 ([Madrid]: En la Imprenta Nacional, 1822), 337-338.

${ }^{52}$ La afición por estos juegos literarios y su inversión fue compartida con otros liberales, que usaron artimañas literarias para urdir toda una crítica política y social. Un ejemplo de ello es el de Bartolomé José Gallardo, Diccionario crítico-burlesco (Cádiz, 1811). El escribir un "Arte de dicharachos" era situarse de lleno a favor de los refranes y dichos populares. Fueron numerosos los autores que atacaron esas "groserías y dicharachos de verduleras", de gentes sin educación, como escribió sobre Juan López Cancelada, redactor de la Gaceta de México, José Guerra en su Historia de la revolución de Nueva España, antiguamente Anáhuac o Verdadero origen y causas de ella con la relación de sus progresos hasta el presente año de 1813, vol. 1 (Londres, 1813), xix.
} 
Anatomía del Pensador, y modo en que se embalzamó, enzacató, y colgó, para eternizarlo.

Retratos del Pensador a caballo, y en otras posturas y actitudes.

Nueva táctica militar cagajonesca, método de afinar y preparar los cagajones para derribar muros, cañones y otros utencilios [sic] que se requieren para que no se ensucien los artilleros. ${ }^{53}$

Inventario de los libros y estantes del Pensador, formado y valuado por su Aprendiz de marras, autor de su defensa. ${ }^{54}$

Herir por los mismos filos. ${ }^{55}$

Muerte pensada o imaginada del Pensador mexicano por sus pecados de pensamiento.

Agua, hirviendo para los responsos y asperges de tales muertos contrahechos.

Berrinches y ojeriza del Pensador, aún después de muerto, contra el Br. Fernández.

Para finalizar como comedia, y no como entremés (con licencia del difunto Pensador).

Comedia: El casamiento imposible del Br. Fernández con la Pensadora, viuda del Pensador.

México: 1822. Imprenta de Ontiveros.

${ }^{53}$ El uso de "cagajones" debe entenderse en sentido burlesco, como unas balas de cañón singulares, con efectos, desde luego, muy contundentes contra sus enemigos. El uso de esta singular munición tiene una trayectoria literaria cuando se intenta motivar la risa. Es un recurso utilizado por José Francisco de Isla en Cartas de Juan de la Encina, incluidas en sus Obras escogidas (Madrid, 1850), carta III escrita en 1732, 420.

${ }^{54}$ El bachiller Fernández ejercía como albacea testamentario, encargado de gestionar el legado y los bienes, anotando y tasando los libros de la biblioteca. En este caso, se propone como táctica publicitaria para fomentar la venta de la biblioteca de un particular tras su fallecimiento. Estos catálogos ofertaban las colecciones a potenciales compradores, sobre todo cuando la biblioteca tenía tal interés como para justificar el costo de la publicación de un catálogo de venta. El término "inventario" fue común en algunos catálogos del siglo XVIII, ver Rodríguez Moñino, Historia de los catálogos de librería.

${ }^{55}$ El título coincide con otro anterior del breve folleto Herir por los mismos filos, ó sea La Abeja Española del dia 28 de Noviembre de 1812, reducida al sentido de la razón (Cadiz, 1812). Una vez más, las alusiones a la Constitución de 1812 están en la raíz de muchas de las obras tomadas como referencia. En cualquier caso, el título coincide con un proverbio conocido que dio lugar a varias versiones literarias, como la recogida por Ventura Ruiz Aguilera, Proverbios ejemplares (Madrid, 1864), 207-222. 


\section{Referencias}

Alba-Koch, Beatriz de. Ilustrando la Nueva España: texto e imagen en el PeriquiIlo Sarniento de Fernández de Lizardi. Cáceres: Universidad de Extremadura, 1999.

Botrel, Jean-François. "Imprimés sans frontières au XIXe siècle (France / Espagne / Amérique Latine)". En Les transferts culturels. L'exemple de la presse en France et au Brésil. Dirección de Valéria Guimarães, 49-62. París: L'Harmattan, 2011.

Buigues, Jean-Marc. "Los anuncios en la Gaceta de Madrid: inicios y desarrollo de la publicidad del impreso en España (1661-1696)". En Edición y propaganda del libro. Las estrategias publicitarias en España e Hispanoamérica (siglos XVII-XX). Edición de Lluís Agustí, Mónica Baró y Pedro Rueda Ramírez, 17-51. Madrid: Calambur, 2018.

Candaux, Jean-Daniel. "Le premier âge d'or du prospectu". En Le livre entre le commerce et l'histoire des idées: les catalogues de libraires, $X V^{e}-X I X^{e}$ siècles. Edición de Annie Charon, Claire Lesage y Eve Netchine, 145-186. París: École des Chartes, 2011.

Catálogo de libros exquisitos de la famosa librería Castellana de don Pedro Joseph Alonso y Padilla. Noticia preliminar de Agustín Hevia Ballina. Oviedo, 1977.

Catalogue of Mexican Pamphlets in the Sutro Collection, 1623-1888: with Supplements, 1605-1887. Nueva York: Kraus Reprint Co., 1971. California State Library. Sutro Mexican Collection.

Cayuela, Anne. "De reescritores y reescrituras: teoría y práctica de la reescritura en los paratextos del Siglo de Oro". Criticón 79 (2000): 37-46.

Coral, Lenore. "Towards the Bibliography of British Book Auction Catalogues, 1801-1900". The Papers of the Bibliographical Society of America 89 (1995): 419-425.

El corneta de las imprentas. Reflexiones joco-serias. México: Imprenta de D. Juan Bautista de Arizpe, 1812. Acceso el 9 de junio de 2020. http://biblioteca digitalhispanica.bne.es.

Domingos, Manuela D. "Os catálogos de livreiros como fontes da história do libro: o caso Dos Reycend". En V Centenário do Livro Impresso em Portugal, 1487-1987: Colóquio sobre o Livro Antigo, Lisboa, 23-25 de maio de 1988: Actas, 305-322. Lisboa: Biblioteca Nacional, 1992. 
Enfermedad, muerte y entierro de la Constitución por el bachiller Sansón Carrasco. Sevilla: Imp. del Correo Político a cargo de Manuel Valdivares, 1814.

Fernández Arias, Irma Isabel. "Calas en el pensamiento de Fernández de Lizardi referente a la libertad de expresión". En Actas del XII Congreso de la Asociación Internacional de Hispanistas, 21-26 de agosto de 1995, 176-181. Birmingham, 2007.

Fernández de Lizardi, José Joaquín. Obras, vol. 12: folletos (1822-1824). México: Universidad Nacional Autónoma de México, 1991.

Fernández de Lizardi, José Joaquín. Some Newly Discovered Poems and Pamphlets of J. J. Fernández de Lizardi (El Pensador Mexicano), prepared under the direction of Paul Radin. [San Francisco: California State Library, 193?].

Fowler, Will. Mexico in the Age of Proposals, 1821-1853. Westport, CT; Londres: Greenwood Press, 1998.

Fumaroli, Marc. Las abejas y las arañas: la querella de los antiguos y los modernos. Barcelona: El Acantilado, 2008.

García Garrosa, María Jesús. "Publicidad y venta de novelas en España a finales del siglo XVIII". Bulletin of Spanish Studies 82, 1 (2005): 19-36.

Guiot de la Garza, Lilia. "El competido mundo de la lectura. Librerías y gabinetes de lectura en la Ciudad de México, 1821-1855". En Constructores de un cambio cultural: impresores-editores y libreros en la Ciudad de México, 1830-1855. Coordinación de Laura Suárez de la Torre, 437-510. México: Instituto Mora / Consejo Nacional de Ciencia y Tecnología, 2003.

Giron Barthe, Nicole. "El entorno editorial de los grandes empresarios culturales: impresores chicos y no tan chicos en la Ciudad de México". En Empresa y cultura en tinta y papel (1800-1860). Coordinación de Laura Beatriz Suárez de la Torre, 51-64. México: Instituto Mora / Universidad Nacional Autónoma de México, Instituto de Investigaciones Bibliográficas, 2001.

González Obregón, Luis. Don José Joaquín Fernández de Lizardi (El Pensador Mexicano). México: Ediciones Botas, 1938.

Herrera y Molina, Alonso de. Discursos predicables de las excelencias del nombre de lesus, y de los nombres y atributos de Christo. Sevilla: Gerónimo de Contreras, 1619.

Horn Melton, James van. La aparición del público durante la llustración europea. Valencia: Universidad de Valencia, 2009.

Índice de libros nuevos por diuersos autores impressos en Madrid desde 17 de setiembre de 1665". Biblioteca Nacional de España, ms. 9397, núm. 6. 
Infantes, Víctor. Del libro áureo. Madrid: Calambur, 2006.

Isla, José Francisco de. Historia del famoso predicador Fray Gerundio de Campazas, alias Zotes. Madrid: Imp. de Gabriel Ramírez, 1804.

Jonama, Santiago. Ensayo sobre la distinción de los sinónimos de la lengua castellana. Madrid: Imprenta Real, 1806.

Knabe, Peter-Eckhard. "The Battle of the Books ou la conquête du nouveaux espaces". En L'aube de la modernité, 1680-1760, 5-14. Filadelfia: John Benjamins Publishing Company, 2002.

Manifestacion de los frac-masones. Dedicada para su conversion al Pensador Mexicano. [México]: Imprenta Imperial de D. Alejandro Valdés, 1822.

Marchamalo, Jesús. Tocar los libros. Madrid: Consejo Superior de Investigaciones Científicas, 2008.

Marrero-Fente, Raúl. "Don Catrín de la Fachenda: La ironía como expresión de una normativa vacilante". Acta Literaria, núm. 28 (2003): 107-121.

Ozuna Castañeda, Mariana y María Esther Guzmán Gutiérrez. "Para que todos lean: La Sociedad Pública de Lectura de El Pensador Mexicano". En Empresa y cultura en tinta y papel (1800-1860). Coordinación de Laura Beatriz Suárez de la Torre, 274-284. México: Instituto Mora / Universidad Nacional Autónoma de México, Instituto de Investigaciones Bibliográficas, 2001.

Palau y Dulcet, Antonio. Un folleto raro del librero de Madrid D. Pedro Joseph Alonso Padilla, 1747. Barcelona, 1928.

Palazón Mayoral, María Rosa. Prólogo a Obras, vol. 12: folletos (1822-1824), de José Joaquín Fernández de Lizardi, ix-lvii. México: Universidad Nacional Autónoma de México, 1991.

Parada, Alejandro E. El mundo del libro y de la lectura durante la época de Rivadavia: una aproximación a través de los avisos de la Gaceta Mercantil (1823-1828). Buenos Aires: Universidad de Buenos Aires, Instituto de Investigaciones Bibliotecológicas, 1998.

Peña Díaz, Manuel. José Isidoro Morales y la libertad de imprenta (1808-1810). Huelva: Universidad, 2008.

Pouey-Mounou, Anne-Pascale y Paul J. Smith, editores. Early Modern Catalogues of Imaginary Books: A Scholarly Anthology. Leiden: Brill, 2019.

Radin, Paul. "An Annotated Bibliography of the Poems and Pamphlets of Fernández de Lizardi (1824-1827)". Hispanic American Historical Review 26, núm. 2 (1946): 284-291. 
Rodríguez Moñino, Antonio. Historia de los catálogos de librería españoles (1661-1840): estudio bibliográfico. Madrid: [Artes Gráficas Soler], 1966.

Rojas, Rafael. La escritura de la Independencia. El surgimiento de la opinión pública en México. México: Taurus / Centro de Investigación y Docencia Económicas, 2003.

Ruiz Casanova, José Francisco. Ensayo de una historia de la traducción en España. Madrid: Cátedra, 2018.

Serrai, Alfredo y Fiammetta Sabba. Profilo di storia della bibliografia. Milán: Bonnard, 2005.

Simón Díaz, José. "Hagiografías individuales publicadas en español de 1480 a 1700". Hispania Sacra 30 (1977): 421-480.

Simón Díaz, José. El libro español antiguo: análisis de su estructura. Kassel: Reichenberger, 1983.

Spang, Kurt. "Aproximación semiótica al título literario". En Investigaciones semióticas I: Actas del I Simposio Internacional de la Asociación Española de Semiótica, celebrado en Toledo durante los días 7, 8 y 9 de junio de 1984, 531-541. Madrid: Consejo Superior de Investigaciones Científicas, 1986.

Spell, Jefferson Rea. "Fernandez de Lizardi as a Pamphleteer". The Hispanic American Historical Review 7, núm. 1 (1927): 104-123.

Suárez Rivera, Manuel. Dinastía de tinta y papel. Los Zúñiga Ontiveros en la cultura novohispana (1756-1825). México: Universidad Nacional Autónoma de México, Instituto de Investigaciones Bibliográficas, 2019.

Uribe-Uran, Victor M. "The Birth of a Public Sphere in Latin America during the Age of Revolution". Comparative Studies in Society and History 42, núm. 2 (2000): 425-457.

Vázquez Semadeni, María Eugenia. La formación de una cultura política republicana: el debate público sobre la masonería, México, 1821-1830. México: Universidad Nacional Autónoma de México, Instituto de Investigaciones Históricas / El Colegio de Michoacán, 2010.

Verney, Luis Antonio. Verdadero metodo de estudiar para ser util a la Republica y a la Iglesia ... tomo segundo. Madrid: Joachin Ibarra, se hallara en casa de don Marcos Ruiz de Tejada, 1760.

Winans, Robert B. "The Beginnings of Systematic Bibliography in America up to 1800: Further Explorations". The Papers of the Bibliographical Society of America 72 (1978): 15-35. 
Ya el pensador mexicano se declaró por herege. México: Imprenta de doña Herculana del Villar y Socios, 1822. Acceso el 9 de junio de 2020. http://bibliotecadigitalhispanica.bne.es. $\mathrm{bg}$ 